\title{
Provoca/acciones urbanas
}

Tácticas ascendentes y creativas en

el Centro Histórico de Córdoba,

Argentina

\section{Urban provoca/actions Bottom-up creative tactics in the Historic Center of Córdoba, Argentina}

José IgNACIo STANG*

\begin{abstract}
The irruption and deployment of a kind of creative artistic actions in and with the urban public space of the Historic Center of the city of Cordoba, Argentina at present are explored and analyzed. Developed by social agents belonging to the field of creative economies, the practices investigated constitute a set of actions that entail a transitory and ephemeral character and that allow, in addition, the possibility of carrying out an integrated reading respect to the instabilities in contemporary city.
\end{abstract}

Key words: urban public space, creativity, ephemeral actions, bottom-up tactics

\section{Resumen}

Se explora y analiza la irrupción y el despliegue de ciertas acciones artísticas creativas en y con el espacio urbano público del Centro Histórico de la ciudad de Córdoba, Argentina, en la actualidad. Las cuales son desarrolladas por agentes sociales que pertenecen al ámbito de las economías creativas. Las prácticas indagadas constituyen un conjunto de acciones que conllevan un carácter efímero y transitorio y permiten, además, la posibilidad de realizar una lectura integrada respecto de las inestabilidades en la ciudad contemporánea.

Palabras claves: espacio urbano público, creatividad, acciones efímeras, tácticas ascendentes. 


\section{Introducción}

Nuestro discurso cotidiano se refiere, en parte, a cuestiones relativas o inclusivas de la ciudad y, más específicamente, a sus espacios de uso común donde confluyen nuestras prácticas, encuentros y desencuentros. Con menor frecuencia, pero no por ello menos importante, se habla también de la ciudad actual y sus espacios urbanos públicos en su relación con la creatividad y el arte. Si bien existen actividades notorias que se destacan por su creatividad aplicada, no hay actividad humana que no esté exenta de crear (Wagensberg, 2017).

En el discurso contemporáneo se asumen, de manera práctica y, al hablar del carácter y la realidad de los ámbitos mencionados, una serie de presupuestos y preconceptos que generan la representación y construcción de ciertos límites. Dicha actitud acota nuestras vidas cotidianas y provoca un efecto negativo por no ayudar en el necesario proceso de comprensión de aquellos aspectos críticos de la realidad. Llegar a reconocer el carácter de los límites, tantas veces arbitrario, sería ya un avance, y resulta un desafío que debiéramos proponernos (Latouche, 2014), entendiendo además que el límite no es un punto donde una cosa finaliza, sino un punto de partida desde donde comienza la propia esencia e inicia lo que es colocado dentro de sus límites (Di Felice, 2012).

La ciudad, vista desde los presupuestos y preconceptos referidos, pareciera ser asumida sólo como un espacio que habitamos, como una construcción arquitectónica y urbanística en un espacio más o menos determinado y limitado. Sobre ella se proyecta la historia de una comunidad móvil y los discursos institucionales que tienden, en el mejor de los casos, a un embellecimiento o, muchas veces, a una adecuación de su imagen con tendencia a una espectacularidad. Sobre los espacios urbanos de uso común (habitualmente denominados espacios públicos) una primera consideración, apoyada en una visión estatal en nuestras sociedades latinoamericanas, parte de la diferenciación entre la vida pública y la vida privada, es decir, entre la administración del espacio por parte del Estado y la vida cotidiana de la sociedad en su intimidad. Desde estos y otros supuestos, transitamos la ciudad y la transformamos, sin que mute mayormente aquella noción primera de ciudad que describe el espacio que está por fuera de nuestra vivienda, el público, simplemente como aquel por el que necesariamente debemos transitar para ir desde un punto a otro. Si bien la anterior afirmación puede parecer la descripción de una aproximación empírica un tanto inocente, no deja de constituirse como el lugar común desde donde inicialmente suele pensarse la ciudad.

En relación a la creatividad, se debe tener la precaución de establecer que no todo vale bajo el amplio y ambiguo paraguas que acoge las ideas 
(Wagensberg, 2017). En este sentido, la creatividad implica siempre una preocupación por el mundo de las ideas, pero no significa que todo lo que se crea sea importante o trascendente. Sobre los aspectos referidos a la creatividad y al arte, frecuentemente se construyen aproximaciones iniciales más o menos inocentes, ingenuas, ligeras e interesadas que, por lo general, se sostienen con un hablar cercano a la crítica, ya que todos en mayor o menor medida somos críticos y artistas (Groys, 2016). Sin embargo, cuando la proximidad de la experiencia es mayor (al involucrarnos e incluir a la ciudad en su génesis), la crítica se proyecta y construye sobre lo contemporáneo. Uno de los resultados más habituales es el de un desconocimiento de dicha realidad, en el que se disputan y apelan categorías, se emiten juicios inestables y por momentos contradictorios. Prevalecen así, formas y conceptos poco operativos y un tanto obsoletos para hacer referencia a ciertas prácticas contemporáneas creativas, que son referidas comúnmente sólo como un despliegue de creatividad de arte sobre y en el espacio urbano público de la ciudad. Así, la ausencia de elementos con los que resulte posible encontrar y establecer referencias estimula la continuidad de los mismos conceptos y, por lo tanto, de los mismos análisis.

La realidad contemporánea establece una línea entre el notable espesor del pasado y la inmensidad interrogativa del futuro. La línea, definida por el presente, es asumida hoy como un tiempo instantáneo y fugaz que se hace manifiesta en cada gesto y acto llamado a contar o hacerse notar. La inseguridad del presente y la incertidumbre sobre el futuro incuban y crían nuestros temores, y nos encuentran carentes de las herramientas que permitan reconquistar el control de lo fugaz (Bauman, 2011). A lo instantáneo se le suma, además, la mutación, el cambio, como una frecuente temática del momento. Se alienta y desea el cambio y todo lo que está relacionado con él, aunque muchas veces puede ser simplemente un primer entusiasmo, más intelectual que vivencial (Llamazares, 2013). Como contrapartida frente a tal cambio, se presenta la tradición, que se constituye, la mayoría de las veces, a partir de una especie de detalle histórico que se adhiere al presente, envuelto en alguna clase de bandera. El pasado viaja en el presente en tránsito hacia un tiempo utópico. En su paso por el presente, la tradición impacta contra el cambio, con el que no siempre dialoga. Como consecuencia, suele surgir una actitud de desconcierto primero y de provocación luego.

En la expresión de la conjunción e interrelación entre tradición y cambio se manifiesta, como representación de dicho vínculo en la ciudad, la centralidad histórica. Asumido como espacio urbano público, el Centro Histórico (en adelante, $\mathrm{CH}$ ) congrega multiplicidad y diversidad de prácticas, expresiones históricas y el despliegue e interacción de distintos 
agentes sociales. Concepto y objeto, el $\mathrm{CH}$ es asumido como un espacio que incluye fenómenos diversos y que, en la inmediatez de la actualidad, constituye una forma de comunicación e intercambio de información (Carrión, 2013; 2008). Opera como un espacio simbiótico, en donde confluyen percepciones y vivencias distintas a partir de símbolos construidos en distintas etapas de la historia y expuestos en sus diferentes capas de la memoria (Gnemmi-Bohogú, 2014). La realidad del CH se presenta en la contemporaneidad como un reto vinculado a distintas variables, donde a partir de una búsqueda en la revalorización de la centralidad histórica como tal, se plantea el desafío de desarrollar nuevas metodologías, técnicas y conceptos que abran nuevas perspectivas analíticas y mecanismos de intervención. Es por ello que es necesario comenzar a evaluar e indagar nuevas maneras en la aproximación a su estudio, no sólo desde lo físico-material, sino también desde los actores y prácticas desplegadas en sus espacios. El cambio frente a la tradición, en un diálogo imprevisto, se expresa y muestra en las centralidades históricas desde distintas y diversas formas. En algunos casos, esa expresión se manifiesta como una provocación al transeúnte a partir de acciones urbanas artísticas y creativas. Desde la excepcionalidad, irrumpen en el ritmo cotidiano, presentando alternativas diferentes de uso y significado y, por lo tanto, necesarias también de ser indagadas.

El presente trabajo expone la síntesis de una tesis doctoral concluida que desarrolla y explora, a través de una lectura integrada, las inestabilidades de la ciudad contemporánea (leída desde la centralidad histórica de la ciudad de Córdoba, Argentina, como espacio urbano público) y la excepcionalidad transitoria de ciertas acciones efímeras (tácticas ascendentes desarrolladas por agentes sociales pertenecientes al ámbito de las economías creativas).

Estructuralmente, el desarrollo del trabajo se divide en tres apartados. El primero, la provocación, aborda la descripción, fundamentación y justificación de la elección del tema-problema. El segundo, las acciones, expone un resumen de tres casos analizados en la tesis doctoral, para dar cuenta sobre el terreno específico de aquellas prácticas descritas de manera teórica en instancias anteriores. El último apartado expone las conclusiones.

La hipótesis inicial propuesta supone que la irrupción excepcional de las denominadas provoca/acciones urbanas en el espacio urbano público del $\mathrm{CH}$ de la ciudad de Córdoba en la actualidad instala una dualidad entre lo real-edificado y lo ficcional-momentáneo en las dimensiones espacio-temporales, en un intento de reclamar la ciudad para redefinir los límites del espacio común habitado, promocionando la producción de un tipo de espacio diferente. Se piensa, además, que la excepcionalidad urbana generada a partir de dichas tácticas ascendentes y creativas propone 
la habitación de espacios y tiempos intermedios, lo que provoca intersticios urbanos en una transformación dinámica a partir de elementos formativos de prácticas sociales, a la vez que se experimentan y conceptualizan espacialidades que contribuyen a relaciones sociales distintas. El desarrollo de estas prácticas propone una ciudad de ciudades, donde emerge una creatividad y arte de carácter colectivo y donde se combinan esfuerzos orientados a la creación de una cultura pública emancipadora, creadora de vínculos solidarios con la otredad y con nuevas formas de vida en común.

Explorar y analizar el accionar de aquellas prácticas desarrolladas como provoca/acciones en el $\mathrm{CH}$ de la ciudad de Córdoba se presenta como uno de los tantos caminos posibles para aproximarse al desafío de construir nuevas miradas y maneras de abordar y estudiar a las centralidades históricas. Estas resultan relevantes, además, como búsquedas para la comprensión de los intercambios y préstamos que se suceden en la lectura de la ciudad actual desde lo urbano público, ya no exclusivamente sobre la distinción o definición de lo público, sino también sobre la apropiación que la ciudadanía ejerce sobre ello (Han, 2016). El despliegue de estas excepcionalidades señala, además, un tipo específico de acción que se caracteriza por un desarrollo de temporalidad efímera, transitoria y fugaz. Desplegadas en un espacio urbano público particular, como es el del $\mathrm{CH}$, a través de un carácter provocativo, producen el desarrollo de un sistema de relaciones entre la acción, los agentes sociales participantes y el entorno construido implicado. Distante de subordinar un campo a otro - espacio, actores y acción - se persigue, por el contrario, dar respuesta a la necesidad de integrar y complementar dichos aspectos a través de una reflexión crítica sobre y desde la ciudad (a través de sus espacios urbanos públicos del $\mathrm{CH}$ ), entendida más como una construcción estética y móvil (donde se despliega la realización e interacción de ciertas prácticas artísticas creativas contemporáneas) que como un hecho físico o un escenario fijo y estático y, en consecuencia, intocable e inamovible.

\section{La provocación}

La génesis de la presente investigación parte de una aproximación al entendimiento de la ciudad de Córdoba, Argentina, en la contemporaneidad, desde la exploración y el estudio de su dinámica urbana actual. Se propone, como primer abordaje, estudiarla a través de los espacios urbanos públicos debido a que, como lugares comunes y compartidos, se considera que es a través de ellos donde la ciudad se desnuda, expone y expresa. Frente a la complejidad y dimensión de tan ambicioso objetivo, se focalizó la mirada en aquellos espacios urbanos públicos pertenecientes 
al área central, más específicamente en aquellos pertenecientes y conformadores del $\mathrm{CH}$ de la ciudad. La justificación del recorte mencionado corresponde en primera instancia a la consideración de que en nuestras sociedades latinoamericanas se está viviendo en la actualidad una revalorización de la ciudad construida y sus centralidades y, dentro de ella con un grado aun mayor, una revalorización de dos tipos de centralidad: la histórica y la urbana-funcional (Carrión, 2001). En algunos casos, como en el de Córdoba, estas centralidades coinciden y se superponen.

Con el regreso de la prioridad a la urbe construida, el CH como centralidad urbana particular cobra un peso singular y su naturaleza cambia (Carrión, 2008) y, por lo tanto, las formas, los caminos y las aproximaciones para observarlo, estudiarlo y analizarlo debieran acompañar también al cambio. El CH, asumido como espacio urbano público, es un ámbito simbólico. Dicho simbolismo se concentra en el tiempo y el espacio, ya que es uno de los ámbitos más significativos y representativos en la ciudad, a tal punto que puede alcanzar a imprimir el carácter de la urbe toda.

El área central de la ciudad de Córdoba (la que incluye en ella al $\mathrm{CH}$ como tal) sigue siendo en la actualidad una síntesis de expresión de la ciudad toda, como lugar privilegiado de referencia con el que se identifica principalmente el conjunto de los ciudadanos. Reúne una serie de atributos, comunes también en otras ciudades, como la reconocible complejidad funcional, la pluralidad de usos, la diversidad morfológica, los objetos edificados arquitectónicos de escala (muchos de ellos devenidos y asumidos como patrimonio), las jerarquías de espacios urbanos públicos y la mayor concentración de flujos de movimiento urbano. Se añade a estas cualidades la característica especial de contener testimonios de todas las etapas de la construcción histórica de la ciudad. Los $\mathrm{CH}$ aparecen como objeto de análisis, estudio e intervención ante la evidencia de su propia crisis o destrucción (Carrión, 2008). Esto ocurre cuando empiezan a perder las funciones centrales que los cualifican, producto de la transformación del patrón de urbanización general de la ciudad en una expansión urbana que extiende sus bordes, que contrasta con la urbanización concentrada del pasado. El $\mathrm{CH}$ de la ciudad de Córdoba en la actualidad se puede leer como un objeto con un alto grado de intervención estética y proyectual, pero con un rumbo poco claro o preciso y, por lo tanto, en crisis. La evidencia de tal observación se expone principalmente en sus espacios urbanos de uso público. En una situación ambiental compleja, sus habitantes y transeúntes — permanentes o transitorios- son piezas claves en su interacción. Enmarcados en la maltratada escenografía del espacio urbano público, poco interactúan y, cuando lo hacen, la mayoría de las veces abusan de él.

$\mathrm{Al}$ hacer una primera aproximación de carácter vivencial al escenario de estudio, transitando y recorriendo los espacios urbanos públicos del 
$\mathrm{CH}$ de la ciudad de Córdoba, se observó como factor común en muchos de sus espacios una serie de excepciones a la tradición, expresadas a través de prácticas y acciones efímeras. Formuladas a la manera de relatos urbanos y prácticas simbólicas, las acciones observadas parecían dejar ciertas marcas cualitativas distintivas de una relación con el entorno, lo que propone una imagen de la ciudad no sólo heterogénea, sino que también reconocida en la experiencia y el recorrido. En su temporalidad de ejecución transitoria o efímera, accionadas con un marcado carácter provocativo, estas prácticas establecen un particular uso espacial y, por lo tanto, se convierten en una temática rica de abordar, ya que ofrece posibilidades de exploración e indagación. En este sentido, cobra relevancia y riqueza el diálogo inesperado, imprevisto y sorpresivo en la dualidad establecida entre tradición-cambio y efímero-permanente: lo transitorio y fugaz de la acción y su conjugación con lo edificado, mostrado como aquello que posee una supuesta mayor estabilidad y constancia a través de las distintas capas de la memoria asentadas en la cualidad y el simbolismo de las centralidades históricas.

Al carácter de tales acciones se lo identificó como táctica (De Certeau, 2010) por ser una práctica efímera, inesperada, sorpresiva, a diferencia de las estrategias, vistas como acciones de poder sobre el territorio desde la planificación, el gobierno, en un sentido que podría ser asumido como la visión de alguien que mira desde arriba hacia abajo. Además, se les asignó también un marcado carácter ascendente entendido como parte de un sistema emergente complejo (Johnson, 2003), diferente del carácter descendente, desde arriba hacia abajo, como sistema institucionalizado y jerarquizado. La complejidad y el desarrollo de sistemas complejos urbanos (Reynoso, 2015) se asumen en este sentido como una sobrecarga sensorial de estímulos sobre sus habitantes, pero, además, como la capacidad posible de autoorganización a partir de sus interacciones locales cotidianas.

Realizadas por diversos agentes sociales pertenecientes a las artes visuales, plásticas, la arquitectura, el diseño, la comunicación social, la gestión cultural, entre otros, dichas tácticas suelen recibir variedad de denominaciones: acciones, obras, intervenciones, instalaciones, performances, site specific, esculturas, happening, acciones urbanas, entre otros términos posibles. Todos tienen ciertas diferencias entre unos y otros pero, en definitiva, se unifican al ser asumidos como prácticas con un marcado carácter creativo y desplegadas sobre el espacio urbano público en una actitud de acción y reacción. Debido a la limitación y recorte propuestos, al abordar dichos grupos y sus prácticas en su complejidad y heterogeneidad, se hizo necesaria la búsqueda de un concepto como perspectiva posible desde donde indagarlos, agruparlos y limitarlos para poder acceder al estudio de estas acciones desde ciertos parámetros. Se decidió, a partir de un 
análisis e indagación inicial donde se leyó quiénes eran los agentes sociales involucrados, los espacios donde desarrollaban sus prácticas, intereses, proveniencia, profesiones, etc., la elección del emergente concepto de economías creativas (Cunningham et al., 2008), para agrupar acciones y actores diversos y variados. Si bien el término economía creativa fue popularizado por Howkins (2001), los autores mencionados profundizan el concepto y la definen como "un complejo sistema que obtiene su 'valor económico’ a partir de la facilitación de la evolución económica, un sistema que produce atención, complejidad, identidad y adaptación a través del recurso primario de la creatividad" (traducción propia de Cunningham et al., 2008: 17). Es difícil alegar, por lo tanto, que todos los aspectos de la creatividad económica, social o política son generados únicamente (o incluso, principalmente) por los procesos mismos de las industrias culturales y creativas. Por este motivo, siguiendo lo pautado por el PNUDUnesco (2013), ${ }^{2}$ el término economía creativa ${ }^{3}$ será utilizado en esta investigación de manera más abarcadora y en relación con aquellas actividades que impliquen creatividad cultural e innovación. Si bien el concepto tiene rasgos, características e implicancias posibles de ser discutidas, en la presente instancia no se consideró pertinente abordar dicho problema. Se priorizó indagar en la excepcionalidad de las propias acciones, sus actores, el desarrollo de ellas en el espacio, la interacción con los

1 "a complex system that derives its 'economic value' from the facilitation of economic evolution, a system that manufactures attention, complexity, identity and adaptation though the primary resource of creativity" (texto original de Cunningham et al., 2008: 17).

${ }^{2}$ Naciones Unidas busca unificar criterios en la definición y delimitación del concepto economía creativa, junto con la creación de bases estadísticas de ámbito internacional a partir de los Creative Industries Reports, publicados por Programa de las Naciones Unidas para el Desarrollo (PNUDUnesco) en 2008, 2010 y una edición especial en 2013. Las dos primeras la definen como actividades relacionadas con la creatividad cultural y la innovación en el núcleo de lo que comúnmente se denomina industrias culturales y creativas. En la última edición buscan abrir el panorama e incluirla prácticamente en todas las esferas económicas intentando ir más allá de exponerla sólo en lo referido a indicadores económicos.

${ }^{3}$ Aunque el origen de las industrias culturales, embrión del concepto de economías creativas, se encuentra en los trabajos de Adorno (2004), habrá que esperar hasta los ańos setenta para que estas ideas calen en los trabajos académicos y hasta los noventa para que sean absorbidos por el concepto de economía creativa. Dicho término tiene su principal raíz de origen en el interés del gobierno del británico Tony Blair al querer dar un impulso a la puesta en valor de las actividades culturales y en explotar cuestiones relacionadas con los derechos de autor en la creación cultural La utilización inicial del concepto economías creativas, procede del Department of Culture, Media and Sports del Reino Unido, con la aprobación de una agenda de políticas públicas destinadas a su promoción. Se trató de un momento clave para la trayectoria posterior del debate académico y la reorientación de las políticas relativas a la cultura, destacando la influencia del documento Creative Industries Mapping Document en 1998 para la difusión del concepto. De esta forma, se lleva a cabo una asimilación entre sectores económicos, en principio poco relacionados (museos, software, industrias de los videojuegos o arquitectura), que pasarán a formar parte de la emergente economía creativa, en la que el componente no cultural tiene mayor peso en el valor acumulado de estos sectores, que se benefician de lo que genera la cultura y acogen a una cierta protección del poder público con base en los derechos de autor (Prada-Trigo, 2015). 
ciudadanos y las consecuencias sobre la ciudad, es decir, estudiar y analizar la excepcionalidad de estas prácticas como promotoras, posibles o no, de una urbanidad alternativa y complementaria.

La comprensión de la urbanidad como objetivo de las ciencias sociales posee diversos enfoques y presenta una serie de divergencias de carácter epistemológico, teórico y metodológico (Lange-Valdés, 2015; Gravano, 2013; Torres, 2003). Interesa en estas disonancias, para un abordaje inicial, el encuentro de un punto de convergencia: el reconocimiento fundamental de la relevancia que las prácticas sociales urbanas tienen como productoras de urbanidad y su importancia para la creación, transformación y apropiación del espacio urbano público. El ser humano es un animal social que se debate permanentemente entre una única identidad individual (él mismo) y varias identidades colectivas (barrio, ciudad, tribu, clan, club, nación, etc.) (Wagensberg, 2017). En este sentido, focalizar la atención en las prácticas sociales urbanas permite acceder al potencial creativo e innovador de la urbanidad, avanzar más allá de la institucionalidad de los procesos formales en el desarrollo urbano y vislumbrar sus dimensiones instituyentes. Los desafíos vigentes planteados para las sociedades del conocimiento resaltan, en este sentido, la necesidad de revalorizar el conocimiento, la innovación y la creatividad como componentes cotidianos en la vida social urbana. Toman así relevancia aquellas perspectivas de abordaje que hacen referencia a las prácticas urbanas cotidianas.

La vinculación entre tácticas ascendentes y economías creativas, como irrupción en las prácticas urbanas cotidianas, permite apuntar a un enfoque crítico y reflexivo en la medida que promueven la observación, la visibilidad y el reconocimiento de aquellos intereses, negociaciones, intercambios y acuerdos no necesariamente explícitos en torno a su formulación y desarrollo urbano. Se evidencia su carácter político y, por lo tanto, también de producción espacial. El surgimiento de ciertas eventualidades y vulnerabilidades, como el actual calentamiento global (económico, social, político y ecológico), ponen en entredicho la sostenibilidad y el impulso de grandes proyectos urbanos. Estas contingencias destacan la necesidad y la relevancia de promover enfoques críticos y reflexivos que atiendan a las condiciones y al desarrollo del complejo contexto territorial actual.

El espacio urbano público, territorio soporte y parte de las acciones a indagar, se asume como espacio de representación. Se puede leer en él la representación del poder, de sus instituciones y símbolos, la representación social de los ciudadanos, de su historia común y de sus intereses ordinarios, y finalmente, la representación de la vida urbana, escenario de las actividades cotidianas y de sus interferencias. La ciudad es un espacio de símbolos reconocidos o reconocibles día a día. Habitar la ciudad exige leer estos símbolos, lo que conduce a su apropiación como espacio de vida, 
espacio doméstico y espacio de aprovisionamiento, pero no solo de bienes, sino también de ideas (De Certeau, 2010). De esta manera, comienza a desentramarse el camino hacia una perspectiva de abordaje del espacio urbano público más adecuada para una sociedad compleja y heterogénea como la actual, un espacio urbano público con un carácter más dinámico. Referirse a espacio simbólico, desde la mirada propuesta, es enfocar la perspectiva en lo intensamente arraigado a lo cotidiano, pero sometido al azar, al juego de los que participan en la vida urbana.

El espacio urbano ya no puede ser, por lo tanto, abordado sólo como lugar, sino más bien, como "un tener lugar de los cuerpos que lo ocupan en extensión y en tiempo" (Delgado, 2007: 13). Cotidianamente, organiza un orden social que es conformado por conductas cuasipredecibles. Son los sujetos los que hacen de la ciudad un lugar practicado y habitado (de constante fluctuación y movimiento), donde el puro acontecimiento los conecta con la arquitectura circundante que transitan a diario como escenario espacial.

El concepto de espacio puede asumirse como uno que liga lo mental y lo cultural, lo social y lo histórico. Si el espacio interviene en el modo de producción, cambia con dicho modo de producción y con las sociedades (Lefebvre, 2013). Las coaliciones peatonales como fiestas, kermeses, procesiones, manifestaciones, piquetes, reclamos sociales o diversas intervenciones efímeras y transitorias tienen lugar en el espacio urbano público como escenario y plataforma de acción, provocación e interacción. Estos acontecimientos no esperables, dislocados, desacomodados, anacrónicos y hasta inadecuados, como una especie de arritmia en lo cotidiano, alteran el anonimato de los sujetos y el sentido asumido y naturalizado que se tiene incorporado acerca de ese lugar intervenido. Sobre aquellas acciones que resultan imprevistas para el ciudadano cotidiano, particularmente, las promovidas por agentes sociales pertenecientes al ámbito de las economías creativas, es sobre las que interesa investigar. Es decir, se buscó indagar en torno de aquella actividad efímera y transitoria que aparece donde no se esperaba que apareciera, lo que permite focalizar y recortar la visión sobre un detalle específico del espacio urbano, interrogándonos: ¿Puede la irrupción de la excepcionalidad en determinados espacios, como el del $\mathrm{CH}$, generar oportunidades para que surjan prácticas de habitar alternativas o disidentes a las actuales? ¿Puede el espacio público de la ciudad, y en particular el del $\mathrm{CH}$, expresar y fomentar prácticas y valores distintos e, incluso, opuestos a los dominantes? Desde la excepcionalidad de las prácticas mencionadas, ¿̇intervienen fuerzas reproductoras o también fuerzas y actos de resistencia o de diferenciación cultural? ¿Qué sucede en la ciudad actual para que la emergencia en la excepcionalidad de estas prácticas se exprese con mayor presencia e intensidad en el espacio urbano público hoy? ¿De qué se valen estas tácticas- 
intervenciones-acciones? ¿Qué proponen? ¿Qué buscan? ¿Qué generan y qué queda? ¿Qué impacto ocasionan? ¿Qué desafíos y retos enfrentan? ¿Podemos referirnos a estas espacialidades propuestas como modeladoras de valores culturales alternativos donde emergen nuevas formas híbridas de cultura-espacio pública?

Desde los estudios de la performance acentúan que para abordar el estudio de estas prácticas se debe considerar tanto el nivel performático como la operatividad performativa de las acciones (González-Menéndez, 2014). Es decir, se tiene que observar no sólo qué son esas acciones urbanas creativas, sino también a qué niveles funcionan y, lo más importante, cómo se fundamentan en la cotidianeidad. La importancia de asentarse sobre tales nociones recae en que, de este modo, se abarcan otro tipo de fenómenos como la construcción de la subjetividad, de las identidades, de la producción y uso espacial, de los usos enunciativos del lenguaje, del activismo político o del uso del cuerpo en la vida cotidiana. Consecuentemente, estas consideraciones permiten también analizar estos fenómenos como procesos sociales.

El análisis de las acciones señaladas puede ser considerado desde la ingenuidad de la forma o de la imagen como un elemento más dentro del espacio de la ciudad, o bien, pueden recuperarse las acciones desde la dinámica de un discurso social que construye comunitariamente sentidos para conformar una imagen de la ciudad. Observar las acciones y prácticas efímeras en el espacio urbano público solamente como expresiones artísticas creativas o marginales que degradan en parte o no la estética de la ciudad puede ser una opción de lectura. No obstante, lo que aquí se propone busca integrar relatos urbanos e imágenes a partir de encontrar relaciones, como también indagar sobre el movimiento y la inestabilidad que exponen estas prácticas al plantear un estado de límite y frontera entre hablar de la ciudad y construir, proponer y promocionar una imagen y vivencia de ella.

$\mathrm{Al}$ aproximarse al estudio de prácticas tácticas de carácter ascendente y creativas, asumidas como provoca/acciones urbanas, desarrolladas durante los últimos años en diversos espacios urbanos públicos del $\mathrm{CH}$ de la ciudad de Córdoba, se expone un despliegue en los límites de la complejidad. Al vincularse con paradigmas artísticos, urbanos, e incluso sociales, estas provoca/acciones generan complejos procesos de creación colectiva, de acción directa, de producción espacial, de solidaridades y redistribución de recursos de diversa índole. Estas prácticas han venido produciendo, cuestionando, inventando y reinventando continuamente lo público en la ciudad, diseminando distintos, diversos y hasta impensados modos de hacer y, sobre todo, concretando intereses y deseos de diversos agentes sociales urbanos individuales y colectivos que construyen 
y producen ciudad. Esto conlleva a ser un emergente objeto de estudio potencial y necesario de ser analizado, que poco ha sido aún explorado más allá de la promoción o divulgación de las acciones por sí mismas.

\section{Las acciones}

$\mathrm{Al}$ referirnos al $\mathrm{CH}$, aludimos en su entendimiento a un espacio urbano público de carácter especial y particular, un espacio que no existe en otro lugar de la ciudad con un orden público tan definido, como delimitado y desarrollado. Las políticas actuales y el accionar sobre la ciudad de Córdoba desde el gobierno expresan una involución en la forma de concebir la ciudad y su transformación, tanto respecto de otras ciudades como en comparación con otros momentos de la propia historia urbana. Se suma a ello la indiferencia de buena parte de la población, el retiro de la discusión pública de las instituciones locales (universidad, Colegio de Arquitectos, etc.), la debilitada actuación de los equipos técnicos en los estamentos del estado y la desorientación política. Muchas veces la falta de empatía y formación de aquellos que deciden sobre el destino de la ciudad colaboran y acentúan también para agravar el cuadro de la situación actual. Se podría decir que aun hoy Córdoba es un fenómeno complejo que se debate entre agudas contradicciones: "impulsada hacia el cambio y anclada en la tradición, creciendo desmesuradamente y luchando por mantener su escala, llena de vitalidad y ahogada en su situación de provincianismo, vive a saltos desigualmente, difícilmente" (Waisman, 2011: 114).

Como contrapartida, las manifestaciones ciudadanas desde el universo del arte y los grupos creativos en la calle y en los medios vienen intentando romper, aunque aún tímidamente, aquellas inercias. El centro de la ciudad de Córdoba, lejos de convertirse en un ámbito ajeno y extraño como sí ha sucedido en otras ciudades latinoamericanas, persiste como el lugar de todos en la consideración de gran parte de su población. Esta valoración es, sin lugar a dudas, la principal fortaleza y el principal indicador de que aún se está a tiempo de una transformación positiva. No se trata en la demanda de apuntar a construir espacios públicos estrictamente definidos y rigurosamente cuidados en su estética para ubicar una obra de arte a ser contemplada, ni tampoco solamente de crear condiciones para ubicar un objeto o acción artística. Se trata de todo lo contrario: que el arte y la creatividad pública en su accionar construyan su continente y, al hacerlo, produzcan espacio público. De esta manera, se da la posibilidad de construir significado sobre la ciudad histórica y sobre cada una de sus partes porque el arte público lo es en la medida en que su ubicación (pública) permite el involucramiento del público y de los públicos sin restricción alguna. 
En el sentido de lo enunciado anteriormente, se torna necesario definir espacialidades y prácticas concretas que expresen y recurran a dichas condiciones espacio-temporales para explorar el espacio urbano $\mathrm{CH}$ y localizar no solo sus características dominantes, sino también, sus puntos de ruptura, donde tales características entran en disputa y quedan suspendidas o se invierten. Es por tal razón que se torna necesario un abordaje de estudio de casos que busque dar cuenta sobre terreno específico de aquellas prácticas descriptas de manera teórica, para poder analizar y buscar a partir de ellas elementos y resultados empíricos que permitan verificar o no los supuestos previos e hipótesis planteadas. Se busca poder analizar de manera crítica y reflexiva el proceso complejo que dio lugar al desarrollo de las prácticas a indagar, más que en la evaluación de resultados numéricos o cuantitativos.

Para la selección de los casos de estudio a analizar se realizó una búsqueda a partir de aquellas prácticas desarrolladas por agentes sociales asociados o relacionados al universo de las economías creativas como categoría emergente, posible de agrupar acciones y actores diversos y variados vinculados al desarrollo de prácticas creativas efímeras en la ciudad. Es importante en esta instancia volver a destacar que si bien el concepto y lo que conlleva tiene rasgos, características e implicancias posibles de ser discutidas, no se aborda dicha cuestión para esta investigación, sino que se asume como un universo posible de congregar y concentrar acciones, actores y el desarrollo de un determinado tipo de prácticas en el espacio. Además, es necesario volver a mencionar que, como tácticas, se seleccionaron aquellas consideradas en el espectro de lo artístico-creativo realizado por agentes pertenecientes al universo de las economías creativas, significando esto el recorte de uno de los variados posibles conjuntos de casos a analizar en el espectro de tácticas desplegadas sobre el espacio urbano público del $\mathrm{CH}$ de la ciudad de Córdoba, y entendiendo en dicho sentido que el universo de prácticas tácticas es mayor.

Para el análisis de casos se tomaron como guía y ejes de clasificación los tres niveles de interacción práctica referenciados en el modelo de círculos concéntricos (figura 1) para el ámbito de las economías creativas planteado por Throsby (2001 y 2008), ya que se considera es, en la actualidad, la sistematización que mejor representa al concepto elegido, tanto por ser el de mayor empleo en los trabajos consultados como por la pertinencia de las clasificaciones asignadas. Además de la clasificación a partir de los círculos concéntricos, se seleccionaron acciones que, en su carácter efímero, al finalizar no dejaran rastros físicos en el espacio urbano público. En este sentido, acciones como grafitis o pinturas políticas se excluyeron para el análisis, sin dejar de reconocer que pertenecen a la clasificación de 


\section{Figura 1 \\ Modelo Círculos Conéntricos propuesto por Throsby}
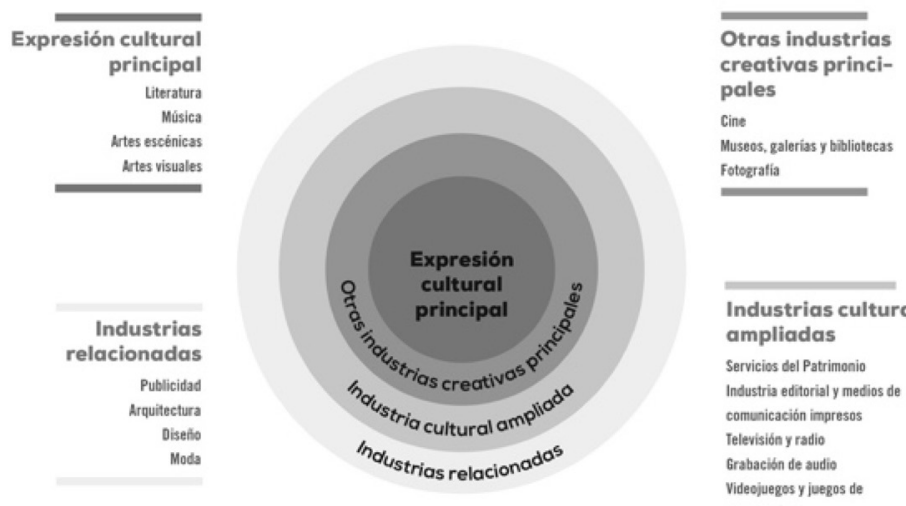

Industrias culturales ampliadas

Servicios del Patrimonio

Industria editorial y medios de

comunicación impresos

Televisión y radio

Grabacion de audio

Videojuegos y juegos de

computadora

Fuente: Throsby, 2001.

tácticas ascendentes y creativas, pero con otro nivel de implicación y relación con las preexistencias.

Debido a las limitaciones asumidas para esta investigación, sólo se expondrá, para cada uno de los niveles establecidos, un caso considerado representativo y que haya sido ejecutado recientemente. Se asume para estas prácticas como factor común su desarrollo en el espacio urbano público junto a su condición de acción efímera y transitoria. Esta realidad conlleva a repensar la manera de reconstruir dichas prácticas desde su condición momentánea o esporádica para su posible estudio o análisis. Se considera de utilidad, en este sentido, la forma común que dicho tipo de acciones asumen para documentar o registrar su accionar efímero por medio del registro fotográfico y ediciones videográficas, características que las convierten en la única comprobación fidedigna de la intervención de los distintos actores, además de los testimonios subjetivos que cada uno de los actores implicados pueda aportar a partir de relatos o narraciones.

$\mathrm{Al}$ ser acciones de carácter efímero y transitorio, se presenta como desafío el poder reconstruir el momento de la acción, como así también el proceso que dio lugar a su construcción. Se suma, además, que en el desarrollo de la práctica se conjugan no sólo aspectos formales o físicos, sino también, aspectos subjetivos y vivenciales de acuerdo con lo que los diferentes actores implicados vivencien. Se propone para cada uno de los casos a estudiar leer el proceso en la construcción, elaboración y ejecución de la práctica, los actores implicados, el lugar donde se desarrolló, el impacto generado y el aporte realizado. Para realizar dicha lectura se utilizó como 
material, a partir del marco teórico elaborado, lo obtenido en entrevistas semi-estructuradas a los protagonistas que desarrollaron cada una de las prácticas, como así también la consulta de documentos, bibliografía o publicaciones referidas a dichas acciones, artículos periodísticos, junto a comentarios y críticas de especialistas como del público participante. Como guía para la exposición de los resultados en cada uno de los casos, y en el desafío de estructurar y sistematizar la información múltiple, se leyeron y analizaron las siguientes variables:

a. Presentación del caso: reseña del caso de estudio, justificación de la elección y exposición de los objetivos buscados.

b. Contexto: descripción del lugar y espacio de emplazamiento.

c. Proceso: construcción, elaboración y ejecución de la práctica.

d. Resultados: evaluaciones, mediciones de impacto o apreciaciones por parte de los autores como del público asistente.

e. Valoración: lectura y análisis de los aportes realizados.

La elección de los casos a estudiar y analizar para cada uno de los niveles se debe, en primer término, al grado de inclusión posible que conllevan, ya sea en actores, espacios o lugares asignados en la ciudad para la ejecución de las prácticas. Por otra parte, además de haber sido desarrollados en el $\mathrm{CH}$ de la ciudad, los tres casos abordan diversidad de actores implicados como escala y jerarquía en los lugares intervenidos. Además, se suma como característica y elemento común para la elección, el haber sido, en parte, partícipe en todas ellas como actor participante, como transeúnte que descubre estas prácticas al irrumpir la cotidianeidad del ritmo urbano. Finalmente, se eligieron por ser también todas ellas ejecutadas en cercanía temporal al inicio de esta investigación (2013), pudiendo tener material posible de ser consultado para su análisis, ya sea bibliográfico, audiovisual, junto al recolectado desde la interacción o vinculación con los promotores de estas prácticas como de quienes participaron en ellas. A partir de la elección de casos, y desde el análisis, el estudio y la valoración de la muestra teórica precisada, se buscó como resultado la réplica o extensión de la teoría emergente. Parte de las relaciones establecidas, como de las fisuras y diferencias encontradas, serán expuestas en las conclusiones. 


\subsection{Nivel 1. Expresión Cultural Principal: Ciudades Visibles (colectivo BigBang Arte)}

\section{a. Presentación del caso}

En 2001 surge en Córdoba, Argentina, el colectivo Proyecto BigBang Arte, una iniciativa de artistas y comunicadores con el fin de formar redes de trabajo entre músicos, artistas visuales, escritores y gestores culturales. Proyecto BigBang Arte trabaja bajo el eje temático de la ciudad, la relación entre quienes la habitan, la idea y apropiación del espacio público, la forma de recorrerla y de reflexionar sobre nuestro lugar en ella.

Producto de intercambios realizados con otras ciudades, se gesta el proyecto Ciudades Visibles como una propuesta que pretende recabar y exponer las diferentes expresiones culturales que ocurren en la ciudad de Córdoba, estableciendo un diálogo e intercambio cultural con otras realidades urbanas del mundo a través de relatos de viajeros, vinculación con emprendedores y gestores culturales, artistas visuales, músicos, y referentes de la escena cultural actual. La propuesta Ciudades Visibles surge con la intención de generar una articulación de redes y espacios culturales. Es un proyecto que, si bien surgió como una intervención puntual en el 2009, su repetición lo convirtió en un proyecto de carácter anual, realizándose todos los años en el CH de la ciudad de Córdoba. No obstante, debido a las limitaciones propuestas para esta investigación, solo se abordará en su análisis a la acción inicial que dio origen al evento en octubre de 2009.

Ciudades Visibles, como acción urbana, busca en su objetivo construir a través del diálogo (en sus múltiples maneras de ser) una nueva mirada sobre la ciudad para resignificarla e interpelarla a través de diversos actores sociales, reconociendo y ocupando espacios en el territorio urbano de lo público. El eje central en cada una de las intervenciones realizadas para Ciudades Visibles contiene al espacio urbano público como eje y categoría a explorar. Esta cualidad de la acción convierte a Ciudades Visibles en un caso a estudiar tanto por la problemática que abordan como por la concurrencia e influencia en la opinión pública, cada vez mayor. Un punto de inflexión en este sentido para el proyecto fue el inicio de la emisión del programa radial Ciudades Visibles, con el que se comenzó a complementar la acción impartida en territorio físico con el abordaje en el espacio público mediatizado, permitiendo seguir entablando nuevas exploraciones, vínculos y creación de redes e intercambio. Junto a las acciones efímeras puntuales que realizan en el espacio urbano público, desde cada proyecto propuesto en Ciudades Visibles, también se desarrolla un foro internacional donde buscan promover la participación y el intercambio sobre la problemática del espacio público en la ciudad de Córdoba. 


\section{b. Contexto}

Para intervenir en el primer ciclo de Ciudades Visibles se eligió como espacio urbano público de la ciudad la plazoleta ubicada frente a la iglesia de la Compañía de Jesús, en la intersección de las calles Obispo Trejo y Caseros. La elección de este lugar se debió a la consideración de la densidad simbólica que tiene como espacio público en el $\mathrm{CH}$ de la ciudad de Córdoba en relación a su localización frente a la Compañía de Jesús.

El espacio de la plazoleta como tal, establece límites definidos por la arquitectura de la iglesia de la Compañía de Jesús, el Museo de la Universidad, la Facultad de Derecho, una serie de locales comerciales y la iglesia-colegio Santa Teresa de Jesús. En este sentido, los límites que ofrece el espacio fueron propuestos a ser explorados como parte de la obra en donde era posible proyectar o ser empleados como soporte donde interactuar. En el mismo sentido, su carácter exclusivamente peatonal permitía desdibujar los límites entre calle-vereda promoviendo otro tipo de exploraciones en la ejecución de la acción. Respecto al uso del espacio urbano, es intenso durante el día por encontrarse en un punto neurálgico de la ciudad y por la cercanía a distintas instituciones educativas como la universidad y el colegio Nacional Monserrat, así como del principal corazón comercial urbano. El habitante que lo transita es principalmente el de la ciudad junto a turistas, por su localización frente a la manzana de la Compañía de Jesús. Durante la noche el uso merma, pero no desaparece, siendo siempre continuo y presente.

\section{c. Proceso}

Si bien la génesis del proyecto Ciudades Visibles surge en 2004, es en 2009, con motivo de la realización del Foro Internacional Saberes, Sabidurías e Imaginarios, desarrollado en la Universidad Nacional de Córdoba, donde BigBang Arte encuentra el espacio para concretar el proyecto a partir de la posibilidad que ofrecía el foro de contar con la participación de especialistas y artistas de diferentes universidades de Latinoamérica. El foro se planteó como objetivo movilizar conocimientos y acciones en torno a creaciones, descubrimientos, alternativas, aprendizajes locales y cambios en procesos globales; así como posibilitar un intercambio entre actores que, desde distintas perspectivas conceptuales, anclajes organizativos y lugares de residencia, aborden temáticas vinculadas al desarrollo local.

El colectivo BigBang Arte participó en el Foro Internacional proponiendo la realización del proyecto interdisciplinario Ciudades Visibles, y a partir de allí surge la acción como tal. La táctica se desarrolló el 29 de octubre en la plazoleta frente a la iglesia de la Compañía de Jesús, como 
espacio urbano público de alto carácter simbólico y representativo, lugar con un alto flujo e interacción peatonal. Se realizaron acciones e intervenciones por videoartistas, músicos, performers y escritores, que abordaron el tema de la ciudad desde el lugar que cada uno ocupaba a partir de su rol, profesión o situación como ciudadano.

La acción específicamente consistió en un soporte donde se expusieron ocho obras de artistas. El soporte era un vinilo desplegable de $3.50 \mathrm{~m}$ x $0.90 \mathrm{~m}$, con bolsillos transparentes donde cada artista dejaba constancia de su intervención efímera, de su ciudad visible, ya sea desde la propia obra o desde el registro realizado. A partir de esos lineamientos, cada artista eligió un formato y una técnica posible de acuerdo con sus competencias y al diálogo que quería generar en torno al proyecto general y al espacio urbano público particular, buscando la expresión individual de cada ciudad visible posible a través de la expresión creativa. Las intervenciones realizadas por cada uno de los artistas fueron video performance-acción y posterior fotomontaje, intervenciones en trama, gráficas experimentales, textos intervenidos, instalaciones sonoras y poesía visual.

\section{d. Resultados}

La acción como tal no tuvo mediciones de impacto como tampoco de público asistente. $\mathrm{Al}$ respecto los autores exponen que: "las mediciones a veces son necesarias, pero lo importante también es preguntarse para qué, para $[\ldots]$ no ser ingenuos respecto de cómo funcionan las cosas. La medición por sí sola no te da un dato por sí solo, no te arroja nada, sino que interesa qué es lo que quieres medir y para qué" (entrevista BigBang Arte, 5 de noviembre de 2016).

En relación con la participación del público, los autores de la obra señalan que participaron artistas y amigos invitados, pero que el principal afluente fue el de la gente que transitaba en ese momento en la peatonal y se encontraba con la obra: "además del público que se pueda convocar desde distintas maneras, está también el público que transita el espacio público, el transeúnte que en ese momento pasa y también es parte del público. El público ocasional, que tal vez es el más interesante de analizar y de repensar. Es el que va engrosando la acción propiamente dicha" (entrevista BigBang Arte, 5 de noviembre de 2016).

Desde BigBang Arte expresan que, como colectivo, el ciclo Ciudades Visibles les permite pensar el espacio de lo público en la ciudad: "siempre algo de eso te queda como vivencia, como una manera distinta de transitar la ciudad, ocasional, diferente, y eso también es crear espacio público, se crea momentáneamente otro tipo de espacio público, paralelo al espacio público físico rígido, el de todos los días" (entrevista BigBang Arte, 
16 de diciembre de 2016). Como colectivo, en su accionar persiguen pensar la ciudadanía y las distintas relaciones que el ciudadano va estableciendo con el espacio en la ciudad, ya sea el físico o el virtual en los medios, el ciudadano como sujeto de derecho, pero también de demandas.

\section{e. Valoración}

La acción Ciudades Visibles surge como táctica en el espacio urbano público de Córdoba que busca indagar en aspectos tales como la problemática vigente sobre el espacio donde se desarrolla la práctica, la relación habitante-ciudad-habitante y las lógicas cotidianas en el uso de la ciudad. $\mathrm{Su}$ crecimiento a partir de acciones posteriores, como el ciclo de programas en la radio o la diversificación de espacios accionados, expresa el potencial de la práctica, no solo desde la propia disciplina artística en su experimentación, sino también en el vínculo que se va generando con los ciudadanos desde la acción puntual que se realiza una vez al año como de la acción e interacción posterior en el foro y el espacio público mediatizado. Se destaca también el formato interdisciplinario que permite recorrer la ciudad, reflexionar sobre el lugar como ciudadanos en ella y además la interacción con actores de otras ciudades, que comparten cuestiones comunes como diferencias.

La propuesta Ciudades Visibles trabaja principalmente en contra de la progresiva despolitización del espacio público y busca combatir en ese sentido la comercialización y la privatización permanente del mismo; "no concebimos el arte como un simple reflejo de la sociedad. Concebimos el arte como un vehículo para hacer sociedad, para crear futuro, para activar a las personas" (entrevista BigBang Arte, 5 de noviembre de 2015). Se busca experimentar la posibilidad de que toda la gente pueda participar en este doble juego de producir y usufructuar del arte, transponiendo esta frontera que separa al artista del no artista. Explora un cambio que se expresa en las intervenciones artísticas en la calle incentivando al ciudadano común a tomar parte en el hacer de la ciudad, promoviendo una vida urbana que persigue ser más creativa, colectiva y activa en lo político, sumando a ello una forma alternativa al mercado como a la formalidad intrínseca de la ciudad.

A partir de los referentes teóricos, se puede reflexionar desde la propuesta de Ciudades Visibles acerca de los distintos modos de pensar la ciudad, su universo de significados que pueden ser planificados o diseñados (estrategias) y, junto a ello, la dinámica, el movimiento, el tránsito, lo inquieto o inquietante, la aparición de coaliciones peatonales que pueden convertirse en manifestación, en expresión inesperada (tácticas). Mismos que pueden parecer un momentáneo estado de excepción y que, 
sin embargo, son la norma (pragmática) de lo urbano en lo cotidiano, expuesto en y a los actos y los usos frente a la forma (sintáctica y semántica) de la ciudad.

Las acciones propuestas en el ciclo Ciudades Visibles desde BigBang Arte consisten en trabajos públicamente visibles, propuestos sobre la plataforma del espacio urbano público. Son de carácter temporal o efímero, y emplean medios de reproducción masiva como la radio, las redes sociales y la fotografía para ser difundidos. Su repercusión, por otra parte, es más bien contraria y de carácter invisible. Buscan interferir en el imaginario del transeúnte y nutrirlo de vivencias paralelas o alternativas ficcionales a la realidad del momento. Intentan así explorar otros formatos de espacios públicos y, por lo tanto, de preguntas formuladas desde lo socio-simbólico hacia lo físico-funcional.

Estas propuestas representan un espacio de búsqueda alternativo en la ciudad de Córdoba, aún poco explorado y experimentado, más allá de lo

\section{Fotografías 1, 2 y 3}

\section{Distintas acciones realizadas en Ciudades Visibles}
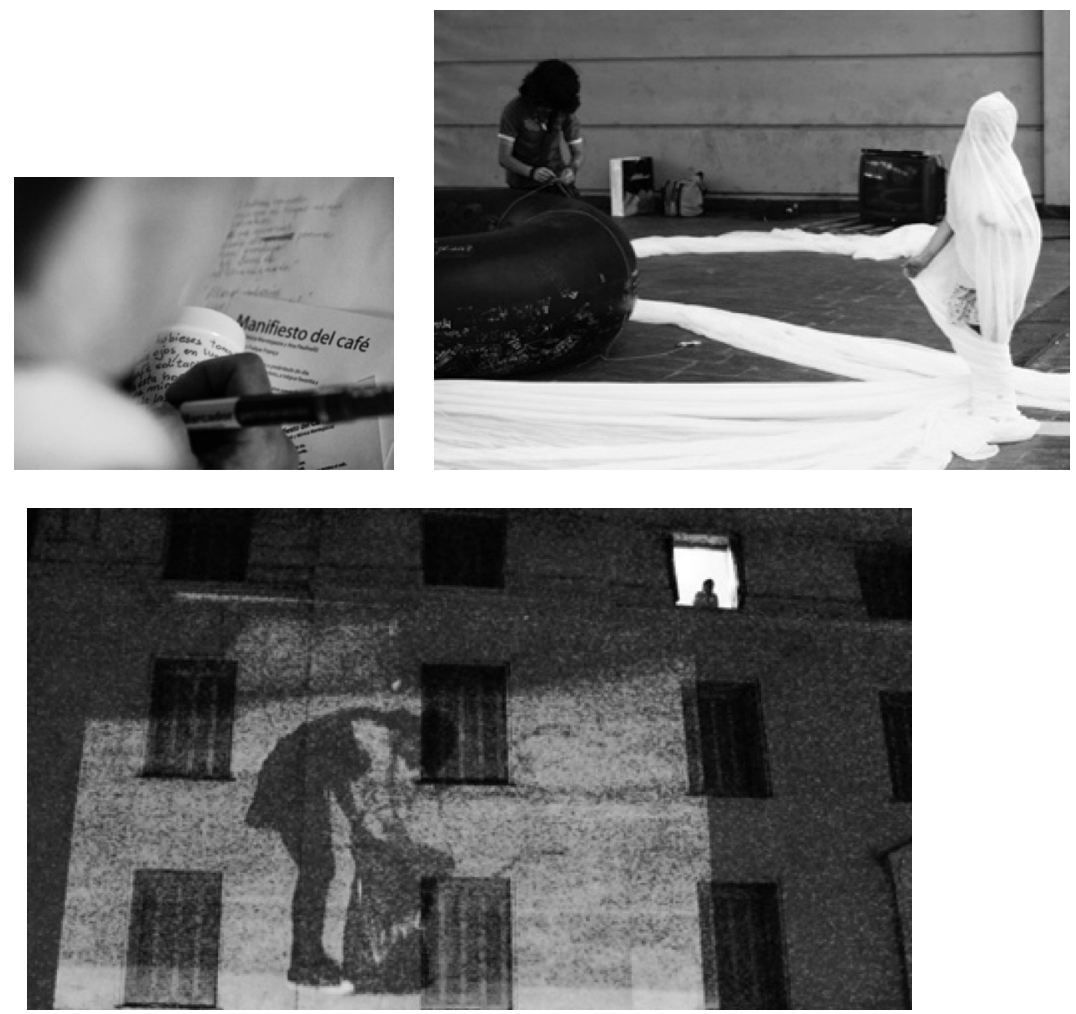

Fotografías: Kremer y García-Cima, 2009. 
que el colectivo pueda ofrecer. Se destaca la vinculación con instituciones y diversos organismos para la difusión y la concreción de las acciones, así como de la búsqueda en construir públicos heterogéneos que descubran maneras diferentes o distintas de vivir lo público en la ciudad. Su objetivo es activar imaginarios y vivencias urbanas distintas en quienes transiten sus acciones efímeras para vincularlos a redes culturales en la construcción de territorios en la ciudad. Como principal característica, el colectivo se destaca en su gestión y comunicación lograda no solo en las redes culturales que establecen, sino que además evidenciados en la concreción de aquellas acciones que buscan accionar o explorar nuevas formas de afrontar el espacio público.

\subsection{Nivel 2. Industrias culturales: Arte Afuera (Centro Cultural España, Córdoba)}

\section{a. Presentación del caso}

En octubre de 2010 el Centro Cultural España, Córdoba (organismo mixto dependiente de la Agencia Española de Cooperación Internacional para el Desarrollo y la Municipalidad de Córdoba) propuso una Muestra Internacional de Arte Contemporáneo denominada Arte Afuera. Se desarrolló en diferentes espacios urbanos públicos de la ciudad de Córdoba, donde participaron artistas locales, nacionales e internacionales. Se abordaron problemáticas referidas al arte contemporáneo en relación con la ciudad y a las nuevas realidades urbanas. La perspectiva de abordaje fue analizada desde las miradas de invitados especialistas provenientes del campo de la sociología, la antropología, el urbanismo, la arquitectura, el arte, la literatura y la gestión cultural. Se planteó como objetivo principal del evento redescubrir la ciudad, asombrarse, reflexionar, dialogar, celebrar y relacionarse en el espacio urbano a través del arte, siempre teniendo a la ciudad como el principal tema de reflexión, análisis y discusión.

La muestra y los equipos de trabajos se estructuraron en cuatro secciones: espacio público (artistas realizaron intervenciones efímeras y transitorias en las calles, plazas y otros espacios urbanos de la ciudad de Córdoba); el panal (edificio de la antigua Escuela de Artes Aplicadas Lino Eneas Spilimbergo, centricamente situado en la peatonal 9 de julio y Rivera Indarte, se encontraba en ese momento abandonado y en desuso, fue el espacio destinado para obras de carácter tecnológico, así como para distintas intervenciones e instalaciones); residencias (fueron invitados artistas a realizar residencias para articular un proyecto de investigación y participación con la comunidad cordobesa a través de instituciones $\mathrm{u}$ 
organizaciones sociales); y auditorio (se abordaron problemáticas actuales del arte contemporáneo, se analizaron temas como la ciudad y las nuevas realidades urbanas, desde la mirada de los invitados especiales como Marc Augé, Ana María Battistozzi, Douglas Crimp, Adrián Gorelik, Lisette Lagnado y Toni Puig Picart).

Durante el desarrollo de la muestra, que duró casi un mes, el espacio urbano público como escenario en el que transcurre con regularidad la vida social de los ciudadanos cordobeses se transformó en plataforma y caja de resonancia del encuentro entre artistas de distintas partes del mundo. Diferentes y diversas calles, plazas, parques, baldíos y edificios de la ciudad, especialmente sobre el $\mathrm{CH}$, fueron señalados, cuestionados e interrogados. En el conjunto y variedad de actividades desarrolladas en la muestra interesan describir, especialmente para el análisis de esta investigación, aquellas prácticas e intervenciones desarrolladas en el espacio urbano público. Se trató de obras físicas transitorias como de performances, eventos u otras intervenciones temporales.

\section{b. Contexto}

La muestra fue llevada a cabo durante el 2010, teniendo a su vez como festejo central en el país a lo largo de todo el año la celebración por el bicentenario de la patria, lo que motivó a que el evento se desarrollara en un clima festivo y de encuentro. El lugar seleccionado para la realización de la mayoría de las intervenciones fueron los espacios urbanos públicos del $\mathrm{CH}$ de la ciudad. Esto se debió principalmente a que el Centro Cultural se encuentra allí, pero además por ser considerado tanto por los organizadores como por los curadores como la principal plataforma de interacción de la ciudad, posible de conjugar los elementos necesarios para el éxito de la muestra.

$\mathrm{Al}$ tener al $\mathrm{CH}$ de la ciudad como el gran escenario y espacio contenedor de la muestra, se aspiró a lograr el agrupamiento de artistas de distintas partes del mundo y que, a través del encuentro y la experiencia relacional con los ciudadanos desde la experimentación en la diversidad de prácticas culturales sobre los espacios urbanos, se genere un profundo intercambio de ideas atravesado por discursos y producciones en un clima de fiesta y celebración que apunte a la concientización de la comunidad al cuidado y uso del espacio urbano público como lugar propio y no ajeno

\section{c. Proceso}

La muestra demandó tres años previos de organización y trabajo. El 8 de octubre de 2010 se inauguró el evento con una visita guiada al edificio 
El Panal, conducida por los curadores junto a otros artistas, medios, empresarios e invitados. Luego, en el patio central del cabildo, se llevó a cabo un acto oficial de apertura y sobre la explanada del cabildo frente a la plaza, con una convocatoria de más de 2000 asistentes, se realizó un concierto de música. La muestra se extendió hasta el 24 de octubre y durante su realización se ejecutaron las distintas actividades para cada una de las secciones programadas. Se describen a continuación, sólo aquellas acciones efímeras y transitorias realizadas sobre al espacio urbano público del $\mathrm{CH}$ :

- A-1 “53167, Fe": En el cruce de las calles Rivera Indarte y Dean Funes, se enterraron fotografías de personas fallecidas y desaparecidas en un cubo de cemento que posteriormente fue sellado. La acción fue presenciada por testigos convocados y gente que transitaba ocasionalmente la peatonal.

- Lara Almarcegui, "Apertura de descampado": se propuso abrir al público espacios clausurados por la planificación urbana. De esta manera, la artista abrió solares en medio de edificios utilizando el baldío como una alternativa de diseño, un lugar abierto, atravesado por el pasado y el futuro.

- Gustavo Artigas, "Voto por demolición": con urnas distribuidas en distintos puntos estratégicos de la ciudad, el artista interpeló al ciudadano con una pregunta que apuntó y buscó como objetivo redefinir el valor estético de la ciudad de Córdoba: ¿qué edificio de la ciudad quisiera ver demolido? Con una votación abierta, la población escogió el edificio que consideraban que por su falta de valor estético quería ver demolido.

- Lucas Di Pascuale, "Ciudadano": se intervino el espacio urbano público con una tarima rodante equipada con micrófonos para ser movilizada por el artista en distintos lugares del $\mathrm{CH}$ de la ciudad de Córdoba. La tarima, disponible para quien quisiera utilizarla, se detuvo en puntos donde se realizaban lecturas y se distribuían materiales receptados, en compañía de conciertos de música y canto.

- Christian Jankowski, "Rooftop rutine”: esta intervención fue ideada durante Performa 2007 en Nueva York, donde se invitó al público a la azotea de su casa para que practicase hula hoop con el mítico juguete de plástico en forma de aro que gira alrededor de la cintura, brazos y piernas. La práctica fue transpolada durante la muestra en cercanías de la Plaza San Martín, en Córdoba, donde se proyectó el video de la intervención realizada en Nueva York, junto a la disposición de aros de plástico para realizar la práctica sobre el espacio público incentivando y motivando al juego en los espacios comunes, junto a la interacción con el otro. 
- Fernandez Sánchez Castillo, "Caudillo": consistió en la presentación de una escultura ecuestre del presidente Hugo Chávez en la plaza de la Intendencia, con la intención de generar un diálogo entre su obra y otros símbolos identitarios de la historia local y nacional del espacio urbano público.

- Tomás Saraceno, "Globos aerosolares": se instalaron, con distintas formas, globos aerosolares (esferas ultralivianas que utilizan la radiación térmica del sol) en el terreno más elevado de la ciudad universitaria. El público podía ser ascendido en estos dispositivos para contemplar la ciudad desde una óptica diferente y poder contemplar la centralidad histórica desde una posición de lejanía.

\section{d. Resultados}

En relación con un posible impacto directo sobre la ciudad no hubo resultados relacionados sobre las intervenciones realizadas, pero sí un quiebre en la manera de intervenir en los espacios urbanos públicos desde la disciplina artística. La muestra cristalizó una serie de procesos que se venían gestionando y que fueron consolidados e impulsados a partir del evento, principalmente la reivindicación de intervenir sobre y con la ciudad, "el antecedente histórico más relevante pertenece a las mítica Bienales y Antibienales de Arte realizadas en la década del '60. La idea de pensar que Córdoba volviera a ser epicentro de un gran acontecimiento artístico nos permitió redescubrir la ciudad" (Luz Novillo Corvalán, en documentación oficial de la muestra, pp. 25).

\section{e. Valoración}

La muestra indagó intensamente la posibilidad de explorar el límite, la frontera de separación entre lo público y privado, e incluso la distinción entre adentro y afuera. Esto se evidenció en la multiplicidad y variedad de obras expuestas en los espacios urbanos públicos como acciones y sitios intervenidos. No obstante, cabe señalar que cada una de las obras fue realizada e ideada previamente pensando en sujetos determinados, con saberes y referencias específicas, los que no siempre concordaron con los que finalmente habitaron las obras, quitando cierto carácter y alguna de las veces pareciendo actuar la espontaneidad pretendida.

La muestra expuso un marcado cruce entre tradición y contemporaneidad, estrategia que permitió enriquecer diálogos al tiempo que favoreció una reflexión sobre el acontecer de la ciudad y su situación actual. Tal vez el logro mayor de la muestra, en una ciudad con una marcada tradición conservadora, haya sido haber sacado la producción artística de sus espacios 
cerrados y haberla llevado a la calle aproximando sus procesos innovadores con el espectador y transeúnte cotidiano de la ciudad en la búsqueda de experimentar prácticas culturales. No obstante, algunos resultados transpolados directamente de otras realidades a la cordobesa sin escalas y sin ninguna adaptación, dan cuenta también de que si bien, tanto desde la promoción de la muestra como de los artistas participantes se radicalizó un discurso, fue inherente la participación de formas variadas en la dinámica global.

La escala de intervención en la ciudad que tuvo el evento fue destacada, significando un quiebre en la manera de intervenir desde el universo creativo de performance, instalaciones y distintos tipos de prácticas y dispositivos en el espacio urbano público cordobés. Se destaca además la

\section{Fotografías 4, 5 y 6}

Acciones y encuentros desarrollados por distintos artistas durante el ciclo
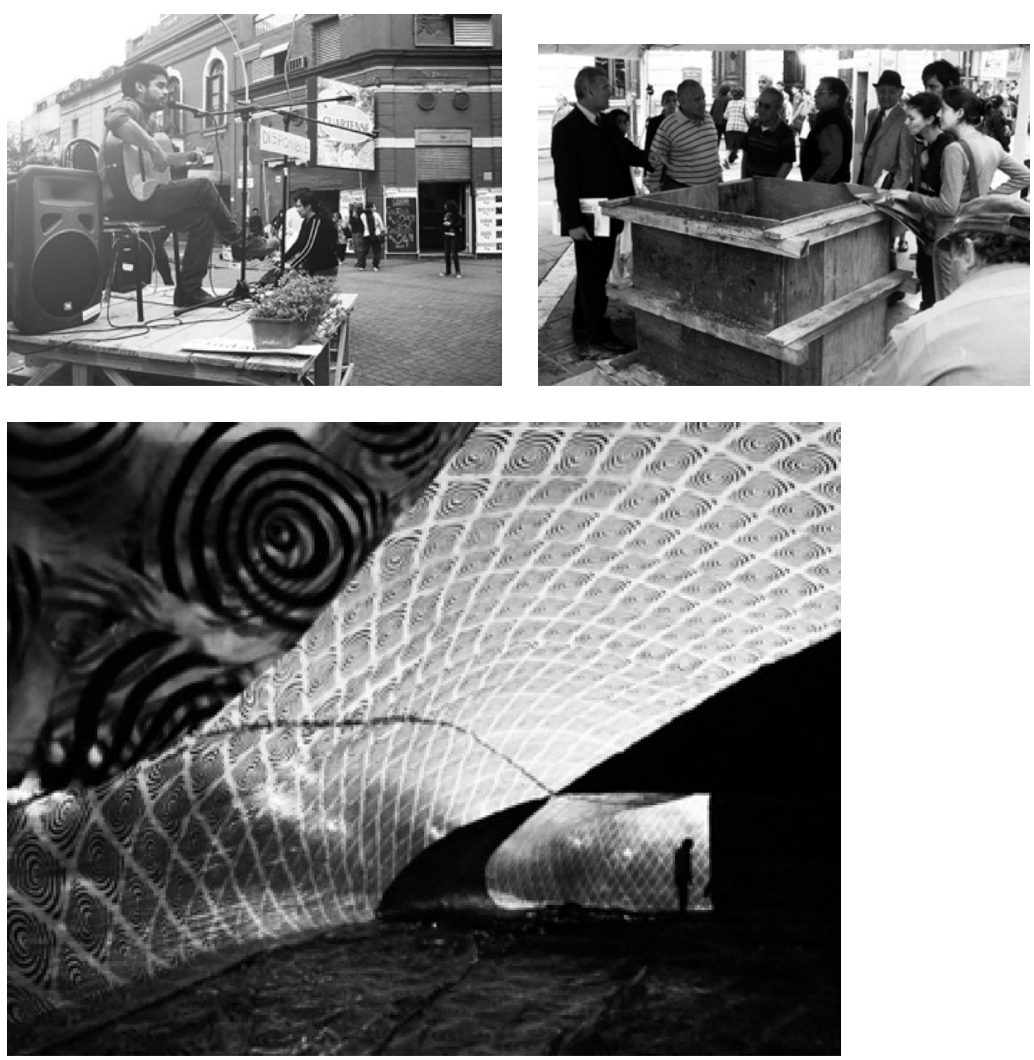

Fotografías: CCEC, 2011. 
interacción con el público, no sólo desde las obras propiamente desarrolladas, sino también desde la reflexión y la crítica en procesos diferentes planteados desde las conferencias y los debates en el auditorio como en las residencias de artistas junto a otras instituciones como escuelas y distintos centros educativos. El rasgo más destacado del evento fue tal vez, aunque no el único, el de disponer desde una actitud efímera y transitoria un juego interactivo de acciones sobre el espacio urbano público donde exploraron e indagaron nuevas prácticas culturales sobre la plataforma de la ciudad.

\subsection{Nivel 3. Industrias relacionadas: Acción mutante (colectivo Colapso)}

\section{a. Presentación del caso}

Colapso es un colectivo de arquitectos que se dedica a indagar y activar nuevas plataformas de reflexión y discusión acerca de la condición urbana contemporánea. Acción Mutante fue un evento organizado por Colapso y financiado en el marco del programa ACERCA-Capacitación para el desarrollo, e impulsada por la Agencia Española de Colaboración Internacional para el Desarrollo (AECID). En el evento se buscó explorar el concepto de patrimonio en relación con el espacio público. La acción persiguió indagar sobre los elementos fundamentales de la relación a explorar, así como posibilidades y abordajes a partir de la realización de intervenciones temporales que provoquen la (re)habitación y (re) activación de espacios públicos degradados y residuales de la ciudad de Córdoba. Se propuso reformular los modos de uso de los espacios públicos a través de hibridaciones programáticas, aprovechando la infraestructura existente modificándole su uso. Descubrir e incorporar nuevos espacios al sistema de espacios públicos tradicionales y fomentar una reflexión crítica sobre la reutilización en arquitectura como estrategia de reactivación urbana.

La invitación a participar en el diseño, la producción y la ejecución de las acciones fue dirigida a estudiantes avanzados de arquitectura, diseño industrial, artistas plásticos, arquitectos y diseñadores industriales, con un cupo de 30 participantes. Bajo la modalidad de trabajo en taller, el púbico participante, en equipos de trabajo y bajo la coordinación y supervisión de profesionales invitados, diseñaron distintas intervenciones para recalificar y resignificar transitoriamente espacios urbanos públicos considerados residuales.

Se planteó profundizar el concepto de patrimonio, identificar y reinterpretar a través del proyecto y las acciones los elementos que otorgan a un espacio urbano la calidad de patrimonio. Además, se propusieron reformular los modos de uso de espacios públicos a través de hibridaciones 
programáticas, reconociendo la conveniencia de aprovechar la infraestructura para otros usos. También se plantearon descubrir e incorporar nuevos espacios al sistema de espacios públicos tradicionales, buscando fomentar una reflexión crítica sobre la reutilización en arquitectura como estrategia de reactivación urbana.

\section{b. Contexto}

Se propuso intervenir en el espacio urbano localizado entre el acceso superior sur de la antigua terminal de ómnibus y el borde oeste de la nueva terminal, ubicado en el desnivel topográfico y el cruce del Bv. Arturo Illia y la Av. Poeta Lugones. Asumido como de interfase, el colectivo propuso adjetivar a tal espacio como puerta de ingreso al $\mathrm{CH}$ desde el sector este de la ciudad. El sector de intervención como tal, se constituye en sus características conformadoras como espacio fragmentado, de difícil accesibilidad y con una aparente falta de carácter. Atravesado y constituido por la superposición de múltiples infraestructuras y espacios de servicio que configuran una serie de fragmentos y elementos que consideraban se constituían para la acción en las potenciales plataformas de intervención: playa de estacionamiento, puentes, escalera, calle, nudo vial, etcétera.

\section{c. Proceso}

Operativamente se trabajó en tres equipos a cargo de dos coordinadores cada uno (un coordinador local y un coordinador externo). Bajo la modalidad de trabajo en taller se dividido la exploración en cuatro etapas: proyecto, producción, registro y reflexión. La acción duró 10 días donde se buscó proyectar y construir una intervención por equipo que dote de contenido y sentido a los lugares residuales seleccionados para Acción Mutante, a la espera de ser (re)utilizados y (re)habitados como espacios urbanos públicos. Tomando al vacío como oportunidad se orientó el trabajo, a partir de las intervenciones y su posterior registro, a descifrar otros modos de operar y de usar el espacio público. Ensayando acciones efímeras o temporales se exploró la búsqueda de espacios transitorios que permitan dotar de contenido y sentido a estos lugares.

\section{d. Resultados}

La organización del evento se presentó como una oportunidad, exitosa en cuanto a concurrencia en la participación, por tratarse de un ámbito poco explorado (el debate y el intercambio junto a la acción en terreno específico). Si bien el colectivo no realizó mediciones cuantitativas de 
impacto, las consecuencias de la acción fueron vistas con una buena evaluación por parte de Colapso.

Por un lado, se logró que la intendencia de la terminal (organismo de gobierno que administra la terminal de ómnibus), junto a la intendencia municipal accedieran y solicitaran la organización de un concurso de ideas a partir de la evaluación positiva de las experiencias realizadas en Acción Mutante. La propuesta no se concretó, pero significó un buen resultado en cuanto a que "tuvo una repercusión directa, aunque luego hubo un cambio de gobierno en la intendencia y no pasó nada. Pero por lo menos llegó a esa instancia. Movilizó a gente que en principio no era muy amigable con la idea de que hagamos una actividad ahí. Pasar de esa postura a la otra fue un buen impacto" (Entrevista a Lucas Carranza, 20 de diciembre de 2016).

Por otra parte, el impacto en el transeúnte, peatón y usuario del lugar se podrían agrupar en dos grandes grupos. Uno, que reaccionó de manera positiva, con un alto grado de apropiación y uso del espacio, "aparecieron personas que se sentaron a almorzar en el lugar, o gente que a la espera de algún colectivo se acostaba a dormir un rato" (Entrevista a Lucas Carranza, 20 de diciembre de 2016), y luego un grupo que si bien no expresó en ese momento su desaprobación, luego lo hicieron por redes sociales,

Tuvimos desde gente que se apropió y expresó aliento para continuar haciendo este tipo de prácticas como gente que nos escribió por las redes sociales diciendo que estábamos juntando basura en el lugar. El espectro fue muy amplio. No obstante, el hecho de que reaccionen frente algo, es un éxito para lo propuesto. Lo importante fue que alguien pasó por ahí, vio que sucedía algo y tomó una postura respecto a eso, sin importar cuál sea. Pero se cuestiona la ciudad por lo menos. Sale de esa actitud pasiva. Probablemente esa persona haya pasado cientos de veces por el mismo lugar, pero en ese momento pasó, vio algo diferente, y lo llevó a buscar la página y a escribirnos. Es un cambio de actitud (Entrevista a Lucas Carranza, 20 de diciembre de 2016).

\section{e. Valoración}

La intervención en el espacio urbano público desde prácticas efímeras o transitorias es un medio interdisciplinar que permite muchos formatos, así como caminos para llegar a un objetivo común: la recalificación, resignificación y uso del espacio público por parte del ciudadano. Cada una de las iniciativas planteadas en el ciclo Acción Mutante parte de estas necesidades previamente analizadas y debatidas, permitiendo realizar una respuesta ante las diferentes realidades urbanas: sociales, políticas, ecológicas, arquitectónicas, filosóficas, etc. Plantear un panorama alternativo de propuestas urbanas que persiga buscar un acuerdo con la realidad social actual fue un objetivo durante la práctica. 
Asimismo, la intervención permitió una relectura de lo inmaterial que cohabita lo tangible arquitectónico percibido a diario. Las intervenciones urbanas efímeras en esa óptica tienen la capacidad de alterar y reformular ese orden de sentidos originarios del espacio preexistente, resemantizándolo.

$\mathrm{Al}$ ser entrevistado, el colectivo define que el espacio de lo público en la ciudad es un espacio de creatividad, entendida no solamente desde la producción artística, sino desde las relaciones sociales y el complejo entramado de interacciones que la ciudad propicia en estos lugares de encuentro, socialización, intercambios culturales, conflictividades y negociaciones. En este sentido, plantean a la ciudad como producto complejo en continua construcción, exponiendo como reto el responsabilizarnos de los espacios que habitamos y hacer de los espacios urbanos públicos lugares para concertar con el Estado el diseño de políticas que no deben ser unilaterales, que deben consultar con el quehacer y el sentir de la gente,

\section{Fotografías 7 y 8 \\ Nuevas espacialidades efímeras desarrolladas durante Acción Mutante}
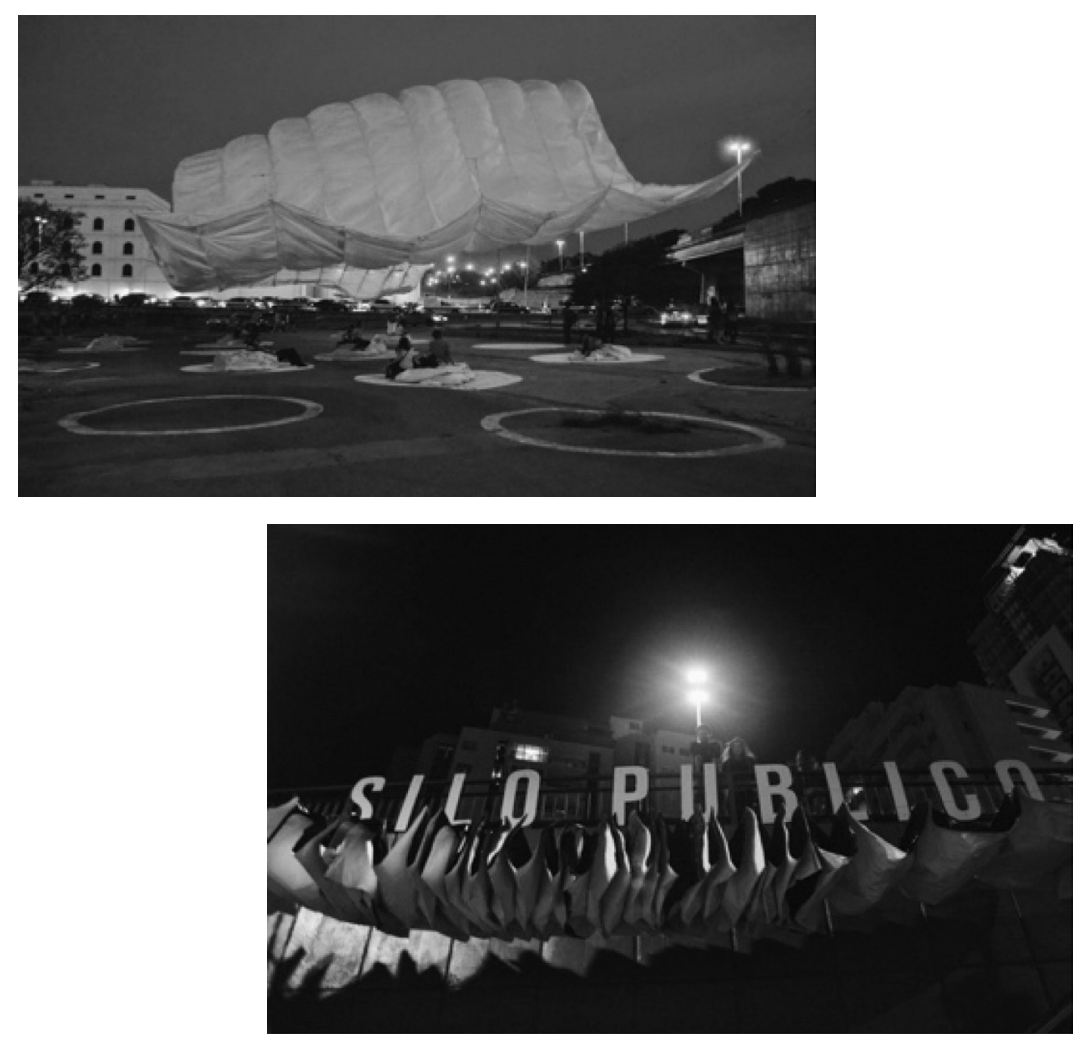


\section{Figura 2}

\section{Localización de acciones analizadas en la centralidad histórica de la ciudad de Córdoba}

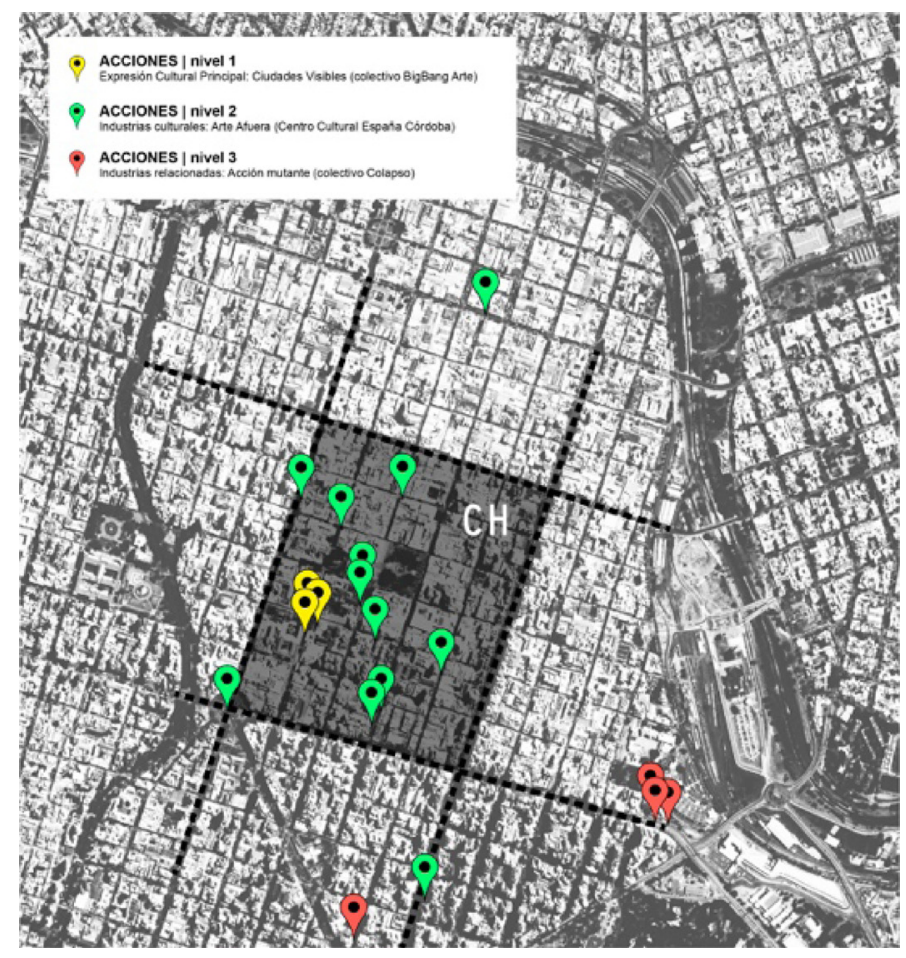

Fuente: Elaboración propia.

y dar respuestas a las demandas culturales que se construyen en la vida cotidiana, y que deben acercar el Estado a la sociedad.

La búsqueda y exploración del concepto patrimonio en relación con el espacio urbano público, llevó al colectivo como a los actores participantes durante la práctica, a recorrer el espacio como una práctica lúdica, ubicándolos en una intersección entre el anonimato y el ser sospechosos. Ubicados en el margen, en la frontera que expone lo edificado, especialmente aquel asumido como patrimonio, en el umbral entre lo público y lo privado, en el medio de estas dos condiciones, se buscó no ya las relaciones de lectura que permiten comprender el espacio y el tiempo de la ciudad, sino descubrir en ella otros espacios que aún están allí por ser descubiertos. Al momento de transitarlos ingresan a nuestro espacio, son significativos y, sin embargo, quizá no volvamos a ellos o quizá ellos ya no estén. La imagen del paréntesis que se construye desde la indagación en la acción desde espacios creativos transitorios resulta entonces útil en cuanto motivan a salir de nuestra 
pasividad en la búsqueda de espacios móviles, de tiempo instantáneo y efímero, y volvamos a ellas sin nada que contabilizar, sin nada que perder, junto con la promesa quizás de una próxima partida donde poder explorar.

\section{Conclusiones}

A partir de los tres casos analizados, y comprendiendo que sólo representan el recorte de un universo mayor, complejo y con otras posibilidades de análisis, las prácticas estudiadas respondieron en su accionar a un activismo político, apelaron a un cuestionamiento de la frontera entre lo que es y no es arte, entre lo público y lo privado, el adentro y el afuera. Jugaron con generar un shock en los transeúntes donde se esperaba que hubiera teatralidad, emplearon ciertas tecnologías para generar yuxtaposición de sentidos sobre un mismo escenario de la ciudad y optaron por el emplazamiento de monumentos efímeros, siluetas o imágenes para materializar hechos vividos socialmente. Ahora bien, ¿qué aportan las tácticas artísticas creativas al espacio urbano público de las estrategias que se expresan en las preexistencias? ¿Qué le permiten a la ciudad de las estrategias institucionalizadas?

Frente a la crisis global contemporánea, la actualidad se presenta como un momento de fragmentos donde se plantea el desarrollo de estas prácticas efímeras como posibilidad de construir umbrales frente a una ciudad de enclaves (Stavrides, 2016). Desde un planteo en la transdiciplinariedad artística y creativa habitada en cada una de las prácticas, en la hibridación entre lo público y lo privado junto con la liminalidad propuesta o la utilización y empleo del espacio urbano público como plataforma y escenario puramente del acontecimiento, estas prácticas colocaron acento en determinados aspectos atravesados por lo social, lo político, lo urbano y lo artístico creativo. Presentaron como resultado formas diversas de repensar el propio arte, pero también lo político y lo urbano. Al tratarse de acciones efímeras y fugaces, poder dar cuenta de ellas de algún modo es también preservarlas y prolongar su accionar transitorio. Conformaron en su excepcionalidad parte del modo de ser (extracotidiano) de la ciudad, visualizado y planteado desde otros modos de percibirla, entenderla o bien transitarla.

Como afirmaba Lefebvre (2013), toda práctica social practica el espacio, lo produce, lo organiza y, sólo puede hacerlo a través de esa herramienta con que sus componentes cuentan y que es fundamentalmente el cuerpo. Por lo tanto, como reflexión final, se puede sintetizar que son acciones que generaron una provocación en los lugares del habitar en cuanto alteraron el ritmo de lo cotidiano, las memorias y los lugares urbanos. 
- Cotidiano: la rítmica permite leer el presente y el futuro (Han, 2015) a través de una suerte de partitura con repeticiones definitorias (Stavrides, 2016). En este sentido, la irrupción de prácticas diferentes a las habituales altera ese ritmo en una provocación, una búsqueda de intereses que se cruzan entre los personales-individuales y los colectivos-sociales. Se generan en este sentido especies de umbrales (Stavrides, 2007; 2016), zonas intermedias en la que ámbitos supuestamente diferenciados (en términos espaciales, dentro y fuera; en términos jurídicos, la ley y la anomía) pierden sus márgenes y se diluyen uno en el otro. Demostraron en su accionar que buscan un despertar (principalmente, aunque no de manera exclusiva) a partir de lo visual sobre la ciudad cotidiana, como instante que irrumpe y rompe la falsa totalidad de percepción, alterando sus automatismos.

- Memorias: las acciones analizadas partieron del reconocimiento del valor potencial que las preexistencias tienen en la ciudad. Alteraron la realidad del ser edificado (arquitectura) reconociendo su condición de preexistencia en cuanto se lo hizo a manera de ensayo, de búsquedas, o más bien de preguntas. A través de las experiencias analizadas, se observó cómo es posible revelar rincones y edificios de la ciudad de profunda carga simbólica, patrimonial y estética de los cuales existe muchas veces un desconocimiento en el andar cotidiano. Junto con ello, mediante el uso de ciertas tecnologías, también se experimentaron el carácter, rol y funcionalidad de sus límites, explorando su capacidad entre el adentro y el afuera y su posibilidad de ser soporte y parte de la obra transitoria, despertar la mirada y comenzar a interrogar, a indagar. Se invitó también así a los transeúntes a descubrirse a sí mismos, como ciudadanos, vecinos y portadores de una herencia (la ciudad como patrimonio) que merece ser cuestionada colectivamente. El patrimonio, considerado desde una visión amplia y compleja, indefectiblemente se asume como aquello que heredamos y que, a su vez, de un modo $\mathrm{u}$ otro reconocemos al valorarlo y darle trascendencia. Dicha idea siempre se ajusta y actualiza en el tiempo y en las circunstancias de forma evidente y manifiesta. La creatividad de las provoca/acciones sobre las preexistencias no es la razón de ser de las mismas, no obstante, interesa y resalta por la actualización a partir de lo que son, cuentan y valen. Trayendo, en este sentido, nuevamente a la memoria e incorporándola a la reflexión sobre la contemporaneidad en relación con el patrimonio edificado en el $\mathrm{CH}$ de la ciudad de Córdoba, resulta inquietante y atractivo el logro generado por las 
provoca/acciones al proponer pensar, experimentar, proyectar e imaginar actualizaciones creativas y consecuentes con el pasado y la conservación de las preexistencias. En este sentido, el valor de sumar a la memoria en el accionar de estas prácticas, importa como variable que, partiendo de asumir a la ciudad como patrimonio, implica como consecuencia asumir que algo debe cambiar al interior de las miradas sobre las preexistencias y su conservación, verificable tal cambio en el ajuste de precisiones conceptuales, metodológicas y operativas.

- Lugares: generaron una (re)semantización de las preexistencias espaciales y edificadas desde una capacidad interpretativa doble, ya que la ciudad no se ocultó, sino que funcionó como escenografía, escenario, ser y parte de la acción. Se buscó crear espacios menos rígidos, ya sea por advertir algunas de las posibilidades inherentes a determinados lugares o porque crearon por sí mismas esas posibilidades que, en ocasiones, entran en confrontación directa con el uso y las regulaciones que tienden a definir determinados espacios. Se transformaron espacios para una acción que no era considerada como autorizada, institucionalizada o formalizada y para que tengan lugar en ellos encuentros creativos, imprevistos e inesperados, lo que en cierta manera colaboró a soltar o liberar esos espacios, a transformarlos en espacios de carácter intermedio. Su existencia, identificada como umbrales, depende de que sean real o virtualmente cruzados.

La palabra creatividad deriva del latín creare, que significa engendrar, producir, crear; crear es producir algo que no existe. El verdadero aporte en buscar provocar al ciudadano a partir de ciertas prácticas creativas y transitorias es, quizás, poder comenzar a pensar y crear una ciudad de ciudades, una ciudad de umbrales, en las que cada persona puede verse identificada dentro de la alteridad y, por lo tanto, dentro de su diferencia, donde se sienta y vivencie motivación y empatía para actuar con libertad y creatividad. Quizás solo tenemos que aprender a ser creativos con la ciudad, sus espacios y el patrimonio edificado, porque la ciudad, asumida como organismo vivo, debe ser vida, y la vida en su génesis es, ante todo, creación. 


\section{Fuentes consultadas}

Adorno, Theodor (2004), Teoría estética. Obra completa, Akal, Madrid, España.

Bauman, Zygmunt (2011), Tiempos líquidos Vivir en una época de incertidumbre, Tusquets Editores, Buenos Aires, Argentina.

Carrión, Fernando (2013), "El patrimonio histórico y la centralidad urbana”, en Blanca Rebeca Ramírez Velázquez y Emilio Pradilla Cobos (comps.), Teorias sobre la ciudad en América Latina, Universidad Autónoma Metropolitana, México, pp. 709-740.

Carrión, Fernando (2008), "Centro histórico: la polisemia del espacio público", Revista Centro-h, núm. 2, Organización Latinoamericana y del Caribe de Centros Históricos, Quito, Ecuador, pp. 89-96.

Carrión, Fernando (ed.) (2001), La ciudad construida. Urbanismo en américa latina, Facultad Latinoamericana de Ciencias Sociales, Quito, Ecuador.

CCEC (Centro Cultural España Córdoba) (2011), ¡Afuera! Muestra internacional de arte contemporáneo en la ciudad de Córdoba, Asunto Impreso Ediciones, Buenos Aires, Argentina.

Colectivo Colapso (2014), Dossier de presentación de Acción Mutante, material inédito, Córdoba, Argentina.

Cunningham, Stuart; John Banks y Jason Potts (2008), "Cultural economy: the shape of the field. In the cultural economy", en Helmut Anheier y Yudhishthir Isar (eds.), The Cultures and Globalization, SAGE Publications, Londres, Inglaterra, pp. 15-27.

De Certeau, Michel (2010), La invención de lo cotidiano I, Universidad Iberoamericana, Ciudad de México, México.

Delgado, Manuel (2007), Sociedades movedizas, Anagrama, Barcelona, España.

Di Felice, Massimo (2012), Paisajes posurbanos, Ediciones del Copista, Córdoba, Argentina.

Gnemmi-Bohogú, Horacio (2014), Sobre las capas de la memoria en el patrimonio edificado, inédito. Córdoba, Argentina. 
González-Menéndez, Leticia (2014), "Performance y acción creativa en el espacio público", LIÑO. Revista Anual de Historia del Arte, núm. 20, Departamento de Historia del Arte y Musicología, Facultad de Geografía e Historia de la Universidad de Oviedo, Oviedo, España, pp. 147-158.

Gravano, Ariel (2013), Antropología de lo urbano, Universidad Nacional del Centro de la Provincia de Buenos Aires, Tandil, Argentina.

Groys, Boris (2016), Arte en flujo, Caja Negra Editora, Buenos Aires, Argentina.

Han, Byung-Chun (2016), La sociedad de la transparencia, Herder, Burzaco, Argentina.

Han, Byung-Chun (2015), La sociedad del cansancio, Herder, Burzaco, Argentina.

Howkins, John (2001), The creative economy, Penguin, Londres, Inglaterra.

Johnson, Steven (2003), Sistemas emergentes, Fondo de Cultura Económica, Ciudad de México, México.

Kremer, Liliana y Elena García Cima (comp.) (2009), Saberes, sabidurías e imaginarios. Territorialidades locales, regionales y globales. Métodos de resolución de conflictos, Advocatus, Córdoba, Argentina.

Lange-Valdes, Carlos (2015), “Comprender la Urbanidad”, Revista Antropologías del Sur, núm. 3, Escuela de Antropología de la Universidad Academia de Humanismo Cristiano, Santiago de Chile, Chile, pp. 137-154.

Latouche, Serge (2014), Limite, Adriana Hidalgo editora, Buenos Aires, Argentina.

Lefebvre, Henry (2013), La producción del espacio, Capitán Swing, Madrid, España.

Llamazares, Ana María (2013), Del reloj a la flor de loto, Del nuevo extremo, Buenos Aires, Argentina.

PNUD-UNESCO (Programa de Naciones Unidas para el DesarrolloUnited Nations Educational, Scientific and Cultural Organization) (2013), Informe sobre la economía creativa, Naciones Unidas, Nueva York, Estados Unidos de América. 
Prada-Trigo, José (2015), "El debate de la creatividad y la economía en las ciudades actuales y el papel de los diferentes actores: algunas evidencias a partir del caso de estudio de Madrid", Investigaciones Geográficas, núm. 87, pp. 62-75.

Reynoso, Carlos (2015), Complejidad y caos, Editorial Sb, Buenos Aires, Argentina.

Stavrides, Stavros (2016), Hacia la ciudad de umbrales, Ediciones Akal, Madrid, España.

Stavrides, Stavros (2007), "Heterotopias and the experience of porous urban space", en Karen Franck y Quentin Stevens (eds.), Loose Space: possibility and diversity in urban life, Routledge, Londres, Inglaterra, pp. 174-192.

Throsby, David (2008), "Modeling the cultural industries", International Journal of Cultural Policy, 14 (3), Routledge, Taylor and Francis Group, Londres, Inglaterra, pp. 217-232.

Throsby, David (2001), "Economics and Culture", Cambridge University Press, Cambridge, Inglaterra.

Torres, Antonio Camou (2003), "Paradigmas e Tendências nos Estudos Urbano-Regionais Contemporâneos", en Carlos Acuña y Alberto Riella (comp.), Territorio, sociedad y Región, Universidad de la República, Montevideo, Uruguay, pp. 13-38.

Wagensberg, Jorge (2017), Teoría sobre la creatividad, Tusquets Editores, Buenos Aires, Argentina.

Waisman, Marina (2011), La ciudad descentrada y después, Editorial Las Nuestras, Córdoba, Argentina.

Recibido: 30 de abril de 2018. Revisado: 15 de junio de 2018. Aceptado: 12 de julio de 2018.

José Ignacio Stang. Doctor en Arquitectura y Urbanismo por la Universidad Nacional de La Plata, Argentina. Actualmente es Becario Posdoctoral en el programa de investigación "Estudios sobre los lugares del habitar y de la memoria”, perteneciente al Centro de Investigaciones y 
Estudios sobre Cultura y Sociedad (CIECS), unidad ejecutora dependiente del Consejo Nacional de Investigaciones Científicas y Técnicas y la Universidad Nacional de Córdoba (Conicet y UNC). Es profesor en la cátedra Introducción a la historia de la arquitectura y el urbanismo A (Facultad de Arquitectura, Urbanismo y Diseño, Universidad Nacional de Córdoba). Sus líneas de investigación actuales son la relación que se establece entre patrimonio edificado-visitante y la realización de indagaciones y reflexiones en torno al patrimonio edificado y las humanidades digitales. Entre sus últimas publicaciones destacan: "El urbanismo como nueva disciplina en Argentina visto desde el especialista Benito J. Carrasco a través del Plan Regulador y de Extensión para la ciudad de Córdoba, 1927”, Revista Cuaderno Urbano, 23 (43) Universidad Nacional del Nordeste, Corrientes y Resistencia, Argentina, pp. 132-150 (2017), "Sentires (in)visibles. La construcción de entornos en espacios socio segregados", Revista Chasqui, núm. 136, Centro Internacional de Estudios Superiores de Comunicación para América Latina, Quito, Ecuador, pp. 413-416 (2017), "Patrones de innovación en los procesos de desarrollo local. Casos de estudio en la provincia de Córdoba", Ingenium, 10 (29), Universidad Santiago de Cali, Cali, Colombia, pp. 41-54 (2017) y "El rol de las economías creativas en la construcción de acciones urbanas en la ciudad", $D E-A R Q$, Revista de Arquitectura de la Universidad de los Andes, núm. 16, Universidad de los Andes, Bogotá, Colombia, pp. 104-119 (2015). 